\title{
A study on effects of osseous configuration in relation to ankle joint instability-a radiographic study.
}

\author{
Karpagam Krishnamoorthy ${ }^{*}$, Vijayaraghavan $\mathbf{V}^{\mathbf{2}}$, Vijayakumar $\mathrm{J}^{3}$ \\ ${ }^{1}$ Department of Research, Saveetha Institute of Medical and Technical Sciences, Chennai, Tamil Nadu, India \\ ${ }^{2}$ Department of Anatomy, Tagore Medical College, Chennai, Tamil Nadu, India \\ ${ }^{3}$ Department of Anatomy, Saveetha Medical College and Hospital, Tamil Nadu, India
}

\begin{abstract}
The ankle joint is the second most important weight bearing region next to the knee joint. There is a natural tendency for forward dislocation of leg bones from the talus which is prevented mainly by two factors-bony and muscular. A total of $\mathbf{1 6 0}$ participants were part of the study after obtaining the written informed consent. 80 participants are having recurrent ankle sprain belong were considered as cases (group I). 80 participants who did not have ankle sprains, but visited the hospital for other complaints were considered as controls (group II). The radiographs of the lateral view of their ankle joint were taken. Significantly higher values of radius of the talus, height of the talus and the tibiotalar angle were reported in males when compared with females of group I $(P<0.001)$. Significantly higher values of radius of the talus $(P<\mathbf{0 . 0 0 1})$, height of the talus $(P<0.001)$ and the tibiotalar angle $(P<0.05)$ were reported in males when compared with females of group II. Comparison of radius and height of the talus, tibiotalar angle between the cases and controls (groups I and II). Radius of the talus was significantly higher in cases when compared to controls $(\mathbf{P}<\mathbf{0 . 0 0 1})$. Height of the talus was significantly higher in cases when compared to controls $(\mathbf{P}<\mathbf{0 . 0 5})$. Tibiotalar angle was significantly lower in cases when compared with controls $(\mathbf{P}<\mathbf{0 . 0 0 1})$. A larger radius, corresponding to a flatter talus, the more the height of the talus and a smaller tibiotalar sector, reflecting less angular coverage of the talus in the tibia, are significantly correlated with ankle instability leading to recurrent ankle sprain.
\end{abstract}

Keywords: Recurrent ankle sprain, Radius and height of the talus, Tibial coverage over the talus.

Accepted on September 12, 2018

\section{Introduction}

The movements of the ankle joint include inversion, eversion, dorsiflexion and the plantar flexion [1,2]. Most of these movements occur around the tibiotalar joint. The osseous alignment of the ankle joint compartment plays a major role behind the stability of anterior compartment of the leg as well the ankle joint, which is the most frequently injured major joint of the body. The ankle joint also forms the main weight bearing area of the body next to the knee joint. It is the most frequently injured joint of the body and it needs lots of factors to stabilize its proper functioning [3,4]. In symmetrical standing, it is said that the line of gravity passes slightly in front of the center of the ankle joint. Therefore there is a natural tendency for forward dislocation of leg bones from the talus which is prevented mainly by two factors-bony and muscular [5]. Any deviation from the normal radius and height of the talus, tibiotalar sector can put an abnormal strain the joint compartment, mainly over the cartilage and capsuloligamentous tissues and lead to spraining of the ankle and surrounding tissues and this is associated with an unstable osseous joint configuration characterized by a larger radius of the talus and a smaller tibiotalar sector [6]. The risk of spraining an ankle depends on both intrinsic factors (hind foot alignment, ligament laxity, muscular force, neuromuscular control and so on) and extrinsic factors (shoes worn, type and intensity of sport, warm up and so on) [7,8]. The shoulder, a rather unstable joint, is characterized by a humeral head that is large compared with the glenoid, whereas in the hip, a stable joint, the femoral head and the acetabulum are of equal size. This suggests that there is a relationship between joint stability and osseous joint configuration [9]. The present study was undertaken to observe the effects osseous configuration in relation to ankle joint instability.

\section{Materials and Methods}

\section{Study design}

Case control prospective study: Study setting: The present study was conducted at the Nathan Super specialty hospital, Salem, Tamil Nadu, India. 
Study participants: A total of 160 patients were selected (March 2017-May 2018) by random sampling technique after obtaining the written informed consent. Group I-80 subjects (47 male, 33 female) who visited the hospital with the history recurrent ankle sprains (minimum 2sprains/month) were considered as cases. Age and sex matched with group II $(n=80)$ who did not have ankle sprains, but visited the hospital for other complaints. Participants with in the age group of 25-35 y and who were willing to participate in the study were included in the study. Those with any mental implants, undergone any surgery involving the lower extremities, any fracture in the lower extremities and pregnant women were excluded from the study. Methods: Digital radiograph of the lateral view of the ankle joint compartment was taken as mentioned in the literature using standard methods.

\section{Ethical consideration}

The study protocol was approved by institutional ethical committee of Saveetha Institute of Medical and Technical Sciences. Written informed consent was obtained from all the participants. Confidentiality of the data was ensured.

\section{Data analysis}

Data was analysed using SPSS 20.0. Unpaired t-test was used to observe the difference between the groups. P value less than 0.05 was considered as significant.

\section{Results}

The results were presented in Tables 1-3. Table 1 presents sexual differences of radius and height of the talus, tibiotalar angle among the subjects who had recurrent ankle sprain (group I). Significantly higher values were reported in males when compared with females of group I $(\mathrm{P}<0.001)$. Table 2 presents the sexual differences of radius and height of the talus, tibiotalar angle among the subjects who did not have recurrent ankle sprain (group II). Significantly higher values of radius of the talus $(\mathrm{P}<0.001)$, height of the talus $(\mathrm{P}<0.001)$ and the tibiotalar angle $(\mathrm{P}<0.05)$ were reported in males when compared with females of group II. Table 3 presents the comparison of radius and height of the talus, tibiotalar angle between the cases and controls (groups I and II). Radius of the talus was significantly higher in cases when compared to controls $(\mathrm{P}<0.001)$. Height of the talus was significantly higher in cases when compared to controls $(\mathrm{P}<0.05)$. Tibiotalar angle was significantly lower in cases when compared with controls $(\mathrm{P}<0.001)$.

Table 1. Sexual differences of radius and height of the talus, tibiotalar angle among the subjects who had recurrent ankle sprain (group I). Data was presented as Mean and SD. $\left({ }^{*} P<0.05\right.$ is significant, ${ }^{* *} P<0.01$ is significant, ${ }^{* * *} P<0.001$ is significant).

\begin{tabular}{lllllll}
\hline Factors & Sex & Number & Mean $(\mathbf{c m})$ & t value & P value \\
\hline $\begin{array}{l}\text { Radius of } \\
\text { talus }(\mathrm{cm})\end{array}$ & the & Male & 47 & 2.68 & 15.18 & $<0.001$ \\
\cline { 2 - 5 } & Female & 33 & 2.41 & & \\
& & & &
\end{tabular}

\begin{tabular}{|c|c|c|c|c|c|}
\hline \multirow{2}{*}{$\begin{array}{l}\text { Height of } \\
\text { talus }(\mathrm{cm})\end{array}$} & Male & 47 & 3.23 & \multirow[t]{2}{*}{36.72} & \multirow[t]{2}{*}{$<0.001$} \\
\hline & Female & 33 & 2.43 & & \\
\hline \multirow{2}{*}{$\begin{array}{l}\text { Tibiotalar sector } \\
\text { (a angle in } \\
\text { degrees) }\end{array}$} & Male & 47 & 85.49 & \multirow[t]{2}{*}{8.4} & \multirow[t]{2}{*}{$<0.001$} \\
\hline & Female & 33 & 82.24 & & \\
\hline
\end{tabular}

Table 2. Sexual differences of radius and height of the talus, tibiotalar angle) among the subjects who did not have recurrent ankle sprain (group II). Data was presented as mean and $S D . \quad\left({ }^{*} P<0.05\right.$ is significant, ${ }^{* * *} P<0.01$ is significant, ${ }^{* * *} P<0.001$ is significant).

\begin{tabular}{|c|c|c|c|c|c|}
\hline Factors & Sex & Number & Mean (cm) & t value & $P$ value \\
\hline \multirow{2}{*}{$\begin{array}{l}\text { Radius of the } \\
\text { talus }(\mathrm{cm})\end{array}$} & Male & 47 & 2.23 & 13.55 & $<0.001$ \\
\hline & Female & 33 & 1.92 & & \\
\hline \multirow{2}{*}{$\begin{array}{l}\text { Height of the } \\
\text { talus }(\mathrm{cm})\end{array}$} & Male & 47 & 2.87 & 10.93 & $<0.001$ \\
\hline & Female & 33 & 2.68 & & \\
\hline \multirow{2}{*}{$\begin{array}{l}\text { Tibiotalar sector } \\
\text { ( } \alpha \text { angle in } \\
\text { degrees) }\end{array}$} & Male & 47 & 88.96 & 9.26 & $<0.05$ \\
\hline & Female & 33 & 86.94 & & \\
\hline
\end{tabular}

Table 3. Comparison of radius and height of the talus, tibiotalar angle between the cases and controls (groups I and II). Data was presented as mean and $S D . \quad\left({ }^{*} P<0.05\right.$ is significant, ${ }^{* *} P<0.01$ is significant, ${ }^{* * *} P<0.001$ is significant).

\begin{tabular}{|c|c|c|c|c|}
\hline Factor & Group & Mean \pm SD & t-value & P-value \\
\hline \multirow{2}{*}{$\begin{array}{l}\text { Radius of the talus } \\
(\mathrm{cm})\end{array}$} & Cases & $2.57 \pm 0.16$ & 17.68 & $<0.001$ \\
\hline & Controls & $2.10 \pm 0.18$ & & \\
\hline \multirow{2}{*}{$\begin{array}{l}\text { Height of the talus } \\
\text { (cm) }\end{array}$} & Cases & $2.90 \pm 0.41$ & 2.16 & $<0.05$ \\
\hline & Controls & $2.79 \pm 0.12$ & & \\
\hline \multirow{2}{*}{$\begin{array}{l}\text { Tibiotalar sector ( } \alpha \\
\text { angle in degrees) }\end{array}$} & Cases & $84.15 \pm 2.33$ & 13.11 & $<0.001$ \\
\hline & Controls & $88.13 \pm 1.38$ & & \\
\hline
\end{tabular}

\section{Discussion}

The current study shows that the stability of the ankle joint could be influenced by its osseous configuration. A larger radius, corresponding to a flatter talus, increased height of the talus, and a smaller tibiotalar sector, reflecting less restraint of the talus in the tibia, are significantly correlated with spraining the ankle and could, therefore, be considered as intrinsic risk factors for ankle joint instability. Further, there is also evidence that a higher talus plays some part, particularly in women [6]. The study also states that, apart from the differences in the parameters among the two groups, gender differences are also seen. Though there are more men than women in this study, many research states that, women tend to sprain their ankle more than men [10-12]. Variables significantly increasing the risk of traumatic leg injuries included generalized joint laxity, low postural sway of the legs, hyperextension of the knee joint, and a low hamstring-to-quadriceps ratio during concentric action [13-15]. Ankle joint is the most commonly injured joint in sports and recreational activities [16-18]. Apart from the 
osseous configuration, even the type of shoes worn can be taken as a factor in determining the joint stability [19]. The ankle joint also forms the main weight bearing area of the body next to the knee joint. It needs lots of factors to stabilize its proper functioning [3]. Given that ankle sprains are the most common injury in sport, this study might be of great importance for the prevention of ankle ligament injuries. People engaging in activities with high risk of ankle sprains and who have an unstable ankle configuration could be recommended to wear ankle-protecting sports equipment $[20,21]$. This intrinsic risk factors-radius of the talus, height of the talus and tibiotalar angle might help doctors and surgeons dealing with patients with recurrent ankle sprain to choose a treatment that is appropriate for individual cases [22]. The balance training program to post ankle sprain can stabilize the ankle joint further preventing the recurrence in future $[23,24]$. In the present study, significantly higher values of radius of the talus, height of the talus and the tibiotalar angle were reported in males when compared with females of group I $(\mathrm{P}<0.001)$. Significantly higher values of radius of the talus $(\mathrm{P}<0.001)$, height of the talus $(\mathrm{P}<0.001)$ and the tibiotalar angle $(\mathrm{P}<0.05)$ were reported in males when compared with females of group II. Table 3-comparison of radius and height of the talus, tibiotalar angle between the cases and controls (groups I and II). Radius of the talus was significantly higher in cases when compared to controls $(\mathrm{P}<0.001)$. Height of the talus was significantly higher in cases when compared to controls $(\mathrm{P}<0.05)$. Tibiotalar angle was significantly lower in cases when compared with controls $(\mathrm{P}<0.001)$.

\section{Conclusion}

A larger radius, corresponding to a flatter talus, the more the height of the talus and a smaller tibiotalar sector, reflecting less angular coverage of the talus in the tibia, are significantly correlated with ankle instability leading to recurrent ankle sprain. We recommend further detailed studies in this area including more samples.

\section{Acknowledgement}

Authors would like to acknowledge their gratitude to the staff of the Research Department to help me in completing the research successfully.

\section{References}

1. Giza E, Fuller C, Junge A. Mechanisms of foot and ankle injuries in soccer. Am J Sports Med 2003; 31: 550-554.

2. Datta K. Essentials of upper and lower extremities (4th Edn.). 2009; 2: 44-46.

3. Baumhauer JF, Alosa DM, Renstroem PA. A prospective study of ankle injury risk factors. Am J Sports Med 1995; 23: 564-570.

4. Garrick JG. The frequency of injury mechanism of injury and epidemiology of ankle sprains. Am J Sports Med 1977; 5: 241-242.
5. Wright IC, Neptune RR, van den Bogert AJ. The influence on foot positioning on ankle sprains. J Biomech 2000 33: 513-519.

6. Arno F, Olaf M. The effect of osseous ankle configuration on chronic ankle instability. Br J Sports Med 2007; 41: 420-424.

7. Beynnon BD. Predictive factors for lateral ankle sprains: a literature review. J Athl Train 2002; 37: 376-380.

8. Hartsell HD, Spaulding SJ. Eccentric/concentric ratios at selected velocities for the invertor and evertor muscles of the chronically unstable ankle. Br J Sports Med 1999; 33: $255-258$

9. Kaminski TW, Buckley BD, Powers ME. Effect of strength and propioception on eversion to inversion strength ratios in subjects with unilateral functional ankle instability. Br J Sports Med 2003; 37: 410-415.

10. Hosea TM, Carey CC, Harrer MF. The gender issue: epidemiology of ankle injuries in athletes who participate in basketball. Clin Orthop 2000; 37: 245-249.

11. Johansson $C$. Training, injury and disease in senior and junior elite orienteers. Sci J Orienteer 1988; 43-53.

12. Smith R, Damodaran A K, Swaminathan S. Hypermobility and sport injuries in junior netball players. Br J Sports Med 2005; 39: 628-631.

13. Valderrabano $\mathrm{V}$, Hintermann $\mathrm{B}$, Horisberger $\mathrm{M}$. Ligamentous posttraumatic ankle osteoarthritis. Am J Sports Med 2006; 34: 612-620.

14. Beynnon BD. Predictive factors for lateral ankle sprains: a literature review. J Athl Train 2002; 37: 376-380.

15. Hartsell HD, Spaulding SJ. Eccentric/concentric ratios at selected velocities for the invertor and evertor muscles of the chronically unstable ankle. Br J Sports Med 1999; 33: 255-258.

16. Nigg BM, Nurse MA, Stefanyshyn DJ. Shoe inserts and orthotics for sport and physical activities. Med Sci Sports Exerc 1999; 31: 421-428.

17. Beynnon B D. Predictive factors for lateral ankle sprains: a literature review. J Athl Train 2002; 37: 376-380.

18. Lundberg A, Svennson OK, Nemeth G. The axis of rotation of the ankle joint. J Bone Joint Surg Br 1989; 71: 94-99.

19. Valderrabano V, Hintermann $\mathrm{B}$, Horisberger $\mathrm{M}$. Ligamentous posttraumatic ankle osteoarthritis. Am J Sports Med 2006; 34: 612-620.

20. Macko VW, Matthews LS, Zwirkoski P. The joint-contact area of the ankle. J Bone Joint Surg Br 1991; 73: 347-351.

21. Halasi T, Kynsburg A, Tallay A. Development of a new activity score for the evaluation of ankle instability. Am J Sports Med 2004; 32: 899-908.

22. Karlsson J, Eriksson BI, Bergsten T. Comparison of two anatomic reconstructions for chronic lateral instability of the ankle joint. Am J Sports Med 1997; 25: 48-53.

23. Magerkurth O, Knupp M, Ledermann H. Evaluation of hindfoot dimensions: a radiological study. Foot Ankle Int 2006; 27: 612-616. 
24. Chaiwanichsiri D, Lorprayoon E, Noomanoch L. Star excursion balance training: effects on ankle functional stability after ankle sprain. J Med Assoc Thailand 2005; 88: 90-94.

\section{*Correspondence to}

Karpagam Krishnamoorthy

Department of Research

Saveetha Institute of Medical and Technical Sciences

Tamil Nadu

India 